\title{
THP-10(T2)
}

\section{A design of scanning system based on the aspherical lens}

\author{
C.Y.Jhuang, J.Y.Chen, T.D.Cheng \\ National Taiwan universality \\ Room 433, Institution of Applied Mechanics, NTU, F., Sec. 4, Roosevelt Rd., Da-an \\ District, Taipei City.106, Taiwan (R.O.C.) \\ ·+88602-33665646, +88602-33665638, cyjhuang@nbm.ntu.edu.tw, jaychen@nbm.ntu.edu.tw, \\ tdcheng@nbm.ntu.edu.tw
}

Abstract -- The goal of this research is implementing the aspherical lens to design a scanning system. It is proposed to make the bio-optical system possess the higher resolution that spherical can't achieve.

\section{INTRODUCTION}

This topic is about optical system design for a biochip scanner. First of all, a light source incident on a rotating dodecahedron mirror, and bended by this rotating mirror. In fig. 1, the designed lenses can focus the incident beam on the specified position. In addition, light can be focused on a spot in the specific range by rotating the dodecahedron mirror. In this article, the commercial software, CODE V, is used to simulate to obtain the best performance.

\section{ANALYTICAL MODEL}

In this system there are some goals to be achieved, the distance between the light source and the rotating mirror is about $20 \sim 25 \mathrm{~cm}$. The geometric figure of the dodecahedron mirror is in fig 2 . The radius of incident light is one of the designed parameter. Distance between the dodecahedron mirror and the focal plane is about $10 \sim 15 \mathrm{~cm}$, the scanning range is about $7.62 \mathrm{~cm}$, the spot size is smaller than $5 \mu \mathrm{m}$, and the scanning linearity will be optimized. In order to achieve these goals, the aspheric lenses are adopted in this scanning system.

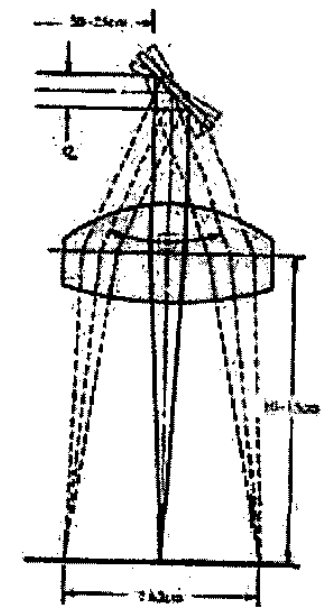

fig 1. optical configuration

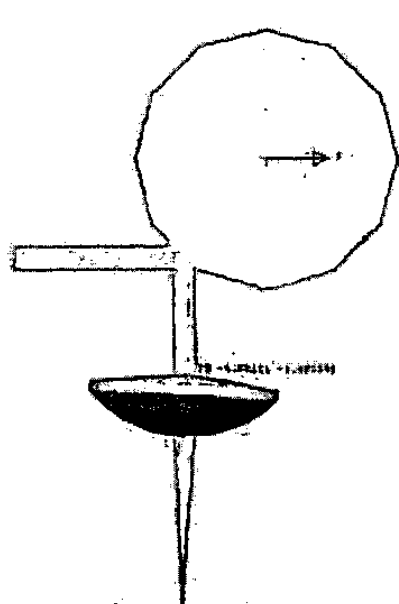

fig 2. The geometric figure of the dodecahedron mirror

\section{RESULT AND DISCUSSION}

In the beginning, eleven surface between stop and image surface are inserted. By changing each surface properties such as thickness, material, surface type, and tilting angle, etc, the preliminary scanning system could be obtained. There are some requirements must be checked, one is spot size, and the other is linearity. From the data list by the software, the maximum spot size is about $3.5 \mu \mathrm{m}$, which is smaller than $5 \mu \mathrm{m}$. Furthermore, the scanning linearity is taken into account. The better linearity means that the distance between each spots would 
be the same as possible as it can. The simulation results show that difference between the maximum and minimum value of spots distance is about $0.27 \mathrm{~mm}$, so the whole system is controlled in the optimized linearity.

Laser is used for the light source, which is simulated as Gaussian function mode. It incidents the dodecahedron mirror in the distance of $250 \mathrm{~mm}$. The material of the glass should be obtained to approach design index. For example, the first aspherical lens is adopted in the ninth surface, which uses the NFK.5_SCHOTT. In addition, the second aspherical lens is adopted in the eleventh surface, which uses the SF4_SCHOTT. By simulating the Gaussian beam into the system, the configuration will be optimized to get the best performance such as spot size, linearity and waist radius, which are shown as follows.

Table 1. Data

\begin{tabular}{|c|c|c|c|}
\hline \multicolumn{2}{|c|}{ waist radius } & \multicolumn{2}{c|}{ linearity } \\
\hline $\mathrm{X}$ & $\mathrm{Y}$ & $\mathrm{Max}=6.392$ & $\mathrm{M}$ Min=6.107 \\
\hline 0.0053 & 0.0037 & & 0.284 \\
\hline
\end{tabular}

Table 2. Gaussian beam propagation

\begin{tabular}{|c|c|c|c|c|c|c|c|c|c|c|c|}
\hline \multicolumn{8}{|c|}{ 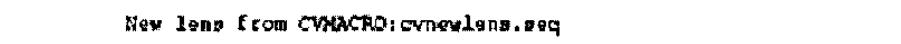 } & \multicolumn{4}{|c|}{ POSITION 6} \\
\hline & \multicolumn{2}{|c|}{ WAVELAMOTH } & \multicolumn{2}{|c|}{$632.8 \mathrm{kan}$} & \multicolumn{3}{|c|}{ DIHEHSIOWS - MLLLTHETERS } & \multirow{2}{*}{\multicolumn{2}{|c|}{$\begin{array}{l}\text { PIELD EOSITIOO } \\
\text { UAIST FADIUS } \\
\text { GEFORE } \\
\text { RERRACION }\end{array}$}} & \multirow{2}{*}{$\begin{array}{c}=10.00 \\
\text { DISTANC } \\
\text { WAIST TO }\end{array}$} & \multirow{2}{*}{$\begin{array}{l}\text { 1. O0) } \\
\text { Cx Troh } \\
\text { O SURFACE }\end{array}$} \\
\hline & $\begin{array}{l}\text { PAOFAEATIOH } \\
\text { DISTABCE TO } \\
\text { NEXT SURTACE }\end{array}$ & $\begin{array}{c}\text { BRhK } \\
\text { ON } 5 \\
x\end{array}$ & $\begin{array}{l}\text { ITUS } \\
\text { CE. } \\
Y\end{array}$ & $\begin{array}{l}\text { BRAH } \\
\text { ORIERTATION } \\
\text { (DBRRELS) }\end{array}$ & $\begin{array}{l}\text { SRVEFTOK } \\
\text { OF } \\
\text { BEFORE } \\
x\end{array}$ & 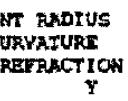 & $\begin{array}{c}\text { PHASE } \\
\text { OR.LNTATION } \\
\text { (OESREES) }\end{array}$ & & & & \\
\hline $\begin{array}{r}O B 3 \\
1 \\
2 \\
3 \\
4 \\
5 \\
6 \\
7 \\
8 \\
9 \\
10 \\
11 \\
12 \\
146\end{array}$ & $\begin{array}{r}250.0005 \\
9.2939 \\
93.6394 \\
0.0000 \\
-96.9285 \\
11.9581 \\
-11.9542 \\
0.0000 \\
-20.3595 \\
-3.1894 \\
-4.6247 \\
-2.8061 \\
-84.9739\end{array}$ & $\begin{array}{l}1.8000 \\
1.8002 \\
2.8002 \\
1.8004 \\
1.8004 \\
1.8002 \\
1.8002 \\
1.8002 \\
1.8002 \\
1.8003 \\
1.9436 \\
2.1851\end{array}$ & $\begin{array}{l}1.80 \\
1.8 \\
2.5 \\
3.61 \\
3.61 \\
3.6 . \\
3.5 \\
2.08 \\
2.08 \\
1.80 \\
2.1 \\
2.7 \\
3.70\end{array}$ & $\begin{array}{l}0.0 \\
0.0 \\
0.0 \\
0.0 \\
0.0 \\
0.0 \\
0.0 \\
0.0 \\
0.0 \\
0.0 \\
0.0 \\
0.0 \\
0.0 \\
0.0\end{array}$ & $\begin{array}{c}\text { Iut } \\
-0.1035 \mathrm{e} \\
-998105.7 \\
-733453.5 \\
-733153.5 \\
-0.101107 \\
1060475.9 \\
1010977.4 \\
1010977.4 \\
936535.08 \\
43.2484 \\
11.8475 \\
15,5656 \\
24.7043\end{array}$ & $\begin{array}{r}\text { IHT } \\
-0.103507 \\
-958105.7 \\
-9314 \$ 3.5 \\
-733453.5 \\
-0.30110 ? \\
1060475.9 \\
1010977-4 \\
1010977.4 \\
996535.08 \\
45.3254 \\
90.1219 \\
86.1949 \\
39.6517\end{array}$ & $\begin{array}{l}0.0 \\
0.0 \\
0.0 \\
0.0 \\
0.0 \\
0.0 \\
0.0 \\
0.0 \\
0.0 \\
0.0 \\
0.0 \\
0.0 \\
0.0 \\
0.0\end{array}$ & $\begin{array}{l}1 . \$ 000 \\
1.3000 \\
1.9000 \\
1 . .000 \\
1 . \$ 000 \\
1.9000 \\
1.9000 \\
1.8000 \\
1.9000 \\
1.3000 \\
0.0030 \\
0.0039 \\
0.0038 \\
0.0053\end{array}$ & $\begin{array}{l}1.8000 \\
1.8000 \\
1.8000 \\
1.0000 \\
1.0000 \\
1.8000 \\
1.0000 \\
1.8000 \\
1.8000 \\
1.8000 \\
0.0032 \\
0.0030 \\
0.0038 \\
0.0037\end{array}$ & $\begin{array}{r}0.0000 \\
250.0005 \\
259.2944 \\
362.9339 \\
35.8338 \\
256.0053 \\
-214.0372 \\
-255.9914 \\
-258.9914 \\
-276.9509 \\
-13.2483 \\
-11.8474 \\
-75.5654 \\
-24.7635\end{array}$ & $\begin{array}{r}0.0000 \\
250.0005 \\
259.2941 \\
352.9338 \\
352.9336 \\
256.0053 \\
-241.0372 \\
-255.9414 \\
-253.9914 \\
-276.3509 \\
-45.3233 \\
-30.1219 \\
-96.1947 \\
-39.5516\end{array}$ \\
\hline
\end{tabular}

Form the above data, the incident beam that expands the radius to $4 \mathrm{~mm}$ incidents into the designed lenses. The $x$ part and $y$ part of Gaussian beam waist radius are $2.4 \mu \mathrm{m}$ and $1.7 \mu \mathrm{m}$ respectively. So it has succeed to achieve all of requirements. They include that the spot size is smaller than $5 \mu \mathrm{m}$, the linearity maintains in the specified range $(0.28 \mathrm{~mm})$, and scanning range is $62.56 \mathrm{~mm}$.

\section{CONCLUSIONS}

The scanning system with higher solution has been designed. The aspherical lenses are adopted to achieve the high performance. The small spot size and the optimized linearity are obtained in the result. For the next stage of this optical system development, the less aspheical lens that ensures the better performance and less cost will be developed. The ultimate goal is to acquire system capabilities for more application.

\section{REFERENCES}

[1] Warren J. Smith, Modern Optical Engineering, McGraw-Hill, New York (2000)

[2] Paul R. Yoder, Jr.,Opto-mechanical systems design, Marcel Dekker, Inc., New York (1993)

[3] Eugene Hecht, Optics, Addison Wesley, New York (2002) 